EPJ Web of Conferences 110,01084 (2016)

DOI: $10.1051 /$ epjconf/201611001084

(C) Owned by the authors, published by EDP Sciences, 2016

\title{
MATHEMATICAL SIMULATION OF HEAT FLOWS IN A BUILDING IN CASE OF HEAT SUPPLY FAILURE
}

\author{
Maxim N. Morozov ${ }^{1, a}$ \\ ${ }^{1}$ National Research Tomsk Polytechnic University, Energy Institute, Lenin Avenue 30, Tomsk, 634050, Russian \\ Federation
}

\begin{abstract}
Investigation of possible thermal modes in a building in case of heat supply failure has been carried out using the developed prognostic complex model. Time characteristics of processes of temperature reduction to critical values (which characterize the conditions of failure of a district heating system) in premises of various configurations have been defined. The influence of heating system structural features and the coolant circulation process at the time of its cooling to critical temperatures has been determined. Mathematical laws, which allow predicting the main parameters of building's useful life according to the heating mode, have been derived. The specific numerical values of investigated processes for climatic conditions with outdoor temperatures from minus $10^{\circ} \mathrm{C}$ to minus $40^{\circ} \mathrm{C}$ have been given.
\end{abstract}

\section{Introduction}

The high accident rate problem at heat networks in Russia has not lost its relevance. This is caused by the fact, that annually there are observed significant measures fluctuations of district heating systems operational reliability. The main reason of negative statistic of district heating systems accident rate is their high physical depreciation. According to statistics it can be observed the following distribution of heat networks accident rate: dilapidated networks $-80 \%$ of all accidents; old networks, requiring replacement $-15 \%$; other networks $-5 \%$. With the spread of modern "non-elevator" individual heating units, power supply outages increasingly influence on the functioning reliability [1].

It is worth noting that the maximum allowable time required to district heating systems recovery is established in normative documents. In case of major accidents there are long breaks of supplying heat, resulting in freeze-up of envelopments and heating systems elements of buildings and constructions.

To solve these problems, as a rule, there are tend to make computer simulating models [2-5]. There are the results of investigations, carried out in two directions: for the overall buildings at "aggregates" [4] and at "control premises" [5, 6]. In investigation [4], carried out at the first direction, there are not considered the following factors: considerable temperature difference between internal and external envelopments, geometric characteristics of the building, heating system configuration. In the second case, it is selected the "control premises" $[5,6]$. In this case, as a rule, there is not considered architectural layout of the building, heat capacity of the heating system main elements and

\section{a Corresponding author : tpu_chm@tpu.ru}


the premise spatial location. It can be also noted the possibility absence of coolant temperature monitoring in the heating system using models [4-6].

When using computer simulation it is possible to achieve relatively low labor costs and increase the duration of the research. There is no effect on building operation safety and its engineering systems, and special monitoring tools for monitoring are not required [7].

In this case, as the study object it is used a mathematical model, which includes a description of building structures, the heating system, taking into account geometrical and thermophysical characteristics, as well as various technical features (heating system configuration, the presence of control systems etc.).

The aim of this work is to investigate the influence of district heating system emergency operation mode on the stability of thermal conditions in a typical administrative building, specifically on the dynamics of air temperature reduction in premises and cooling of the heating system coolant.

\section{Model description}

As a simulation object, a district heating system of a three-floored administrative building with the total area of $9870 \mathrm{~m}^{2}$ and volume of $35.926 \mathrm{~m}^{3}$ has been selected. Heat supply of the building is provided by the central heating unit at the temperature chart $95 / 70{ }^{\circ} \mathrm{C}$. The individual heating unit has been designed under the "independent scheme" [8]. Water is used as a coolant in the heating system internal circuit [9].

The thermal model of the building has been developed to simulate the heating system emergency operation mode of the above object. The application Simulink of the mathematical package Matlab [10] has been selected as a platform for a model.

Figure 1 shows basic blocks of the developed thermal model of the district heating system of the building. The model comprises the following main functional components [11]:

- a heating appliance (radiator);

- a mixer tap;

- a valve;

- a thermal protection block of the premise;

- a weather block;

- a block of the premise temperature mode. 

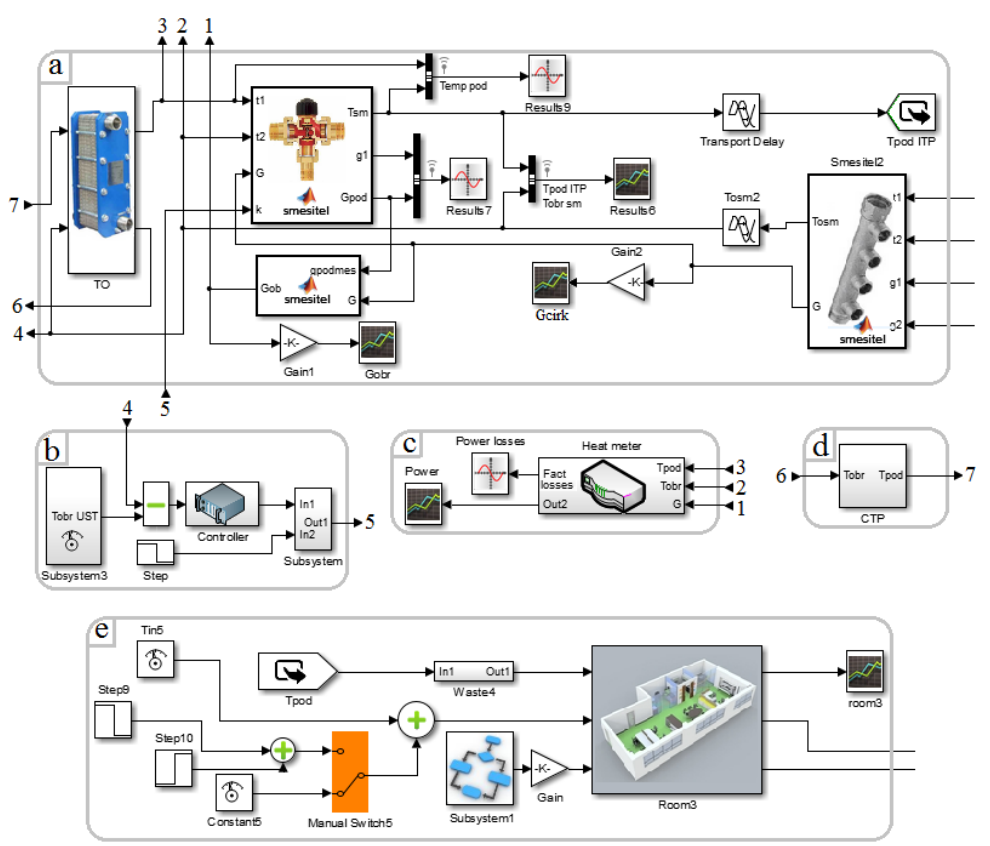

Figure 1. The main thermal model blocks of the district heating system of the building: a - block of individual heating unit elements; $\mathrm{b}$ - heat consumption controller; $\mathrm{c}$ - heat calculator; $\mathrm{d}$ - heat supply source; $\mathrm{e}$ - block of premise model.

\section{Modelling results}

Two groups of premise have been selected for prognostic investigation - from the corner and central parts of the building (Figure 2). The following numeration has been admitted:

- premise no. 1-3 are "corner" on the 1-3th floors respectively;

- no. 4-6 are "central" premises on the 1-3th floors respectively.

Heating appliances within each group are connected in series (vertical single-tube configuration with overhead coolant distribution). Premises are characterized by the area of $52 \mathrm{~m}^{2}$ and identical layout (Figure 2). "Corner" premises have one additional window.

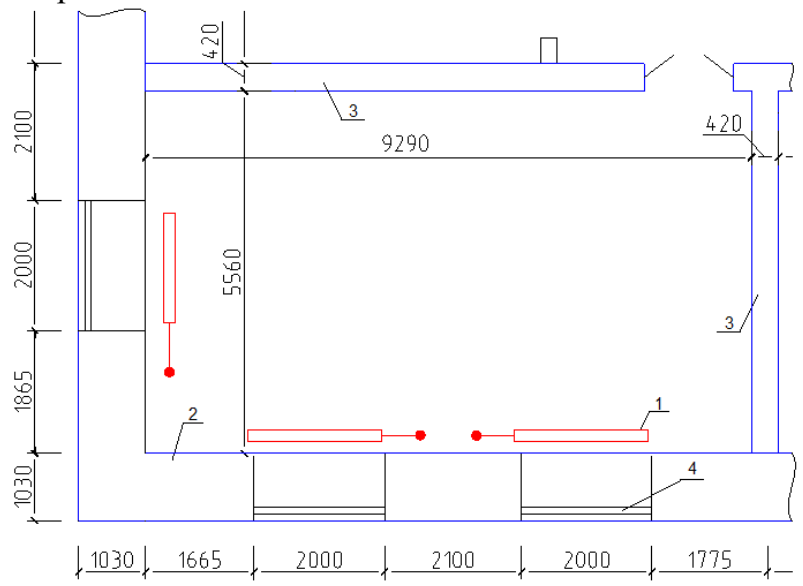

Figure 2. A schematic diagram of a "corner" premise: 1 - heating appliance, 2, 3-interior and exterior envelopments, 4 - dual-pane window. 
To achieve the set purpose of investigations, a series of numerical experiments has been carried out, aimed to analyze the influence of the outside temperature $T_{\text {ext }}$ on temperature reduce dynamics inside the premise and the heating system coolant. Values of $T_{\text {ext }}$ were varied within range from minus $40{ }^{\circ} \mathrm{C}$ to minus $10{ }^{\circ} \mathrm{C}$.

Simulation of heating system emergency operation is at heat supply restriction from the central heating unit. As an example, the results of this simulation of the heating system operating mode at heat supply restriction at 18 o'clock are given below.

Two variants of heating system functioning at heat supply restriction of the individual heating unit from the external heat source were considered:

- while continuing the coolant circulation in the heating system inner loop, even after the start of the emergency mode up to its freezing;

- at the absence of circulation (can be caused by forced shutdown of pumps or by power outage).

The interim simulation results (at $T_{e x t}=-40{ }^{\circ} \mathrm{C}$ and in case of continuous coolant circulation) are shown in Figure 3. Initial air temperature $T_{i n}$ is admitted to be identical at all premises and reaches $20{ }^{\circ} \mathrm{C}$.

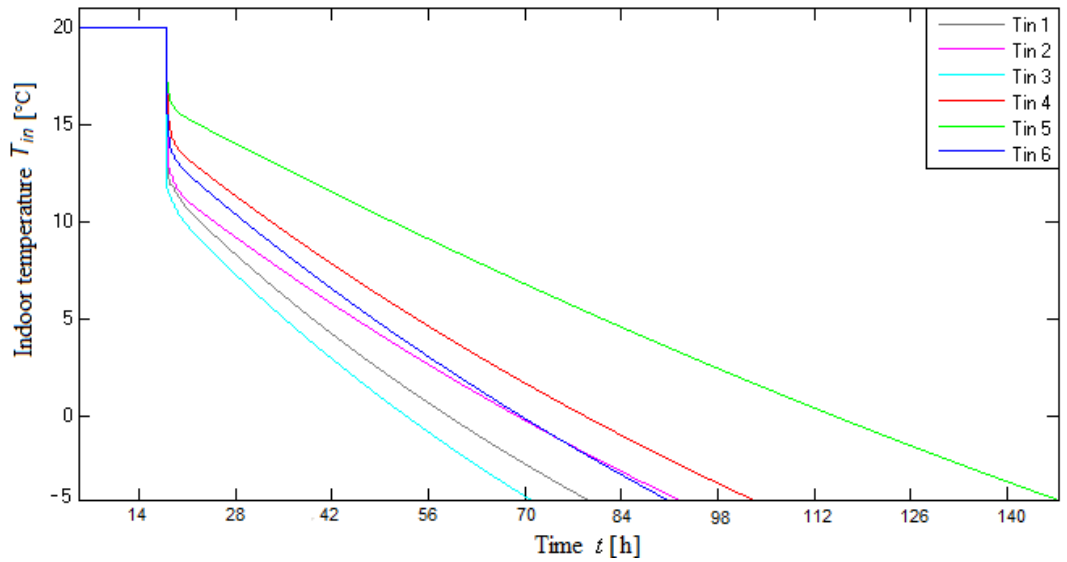

Figure 3. Dynamics of air temperature reduce inside premise at $T_{\text {ext }}=-40{ }^{\circ} \mathrm{C}$ in case of continuous heating system coolant circulation: $T_{i n} i$-air temperature inside the $i$-th premise, where $i=1,2, \ldots 6$.

Maximum cooling dynamics of all of six control rooms is committed for the "corner" premise on the third-floor: air temperature reduction (from the initial value to $0{ }^{\circ} \mathrm{C}$ ) time is $34 \mathrm{~h} 38 \mathrm{~min}$ for the first case (continuous coolant circulation) and $31 \mathrm{~h} 5 \mathrm{~min}$ for the second case (the absence of circulation). The "central" premise on the second floor is characterized by the lowest air temperature reduction intensity: reduction time is $96 \mathrm{~h} 17 \mathrm{~min}$.

Figure 4 shows air temperature inside premises reduction time $t_{d e c}$ dependencies on external disturbing factor $-T_{\text {ext }}$ (for the entire range of values).

While plotting dependence, shown in Figure 4, air temperature reduction time $t_{\text {dec }}$ was recorded at the moment $T_{\text {int }}=0{ }^{\circ} \mathrm{C}$.

It is important to note, that only maximum and minimum values $t_{d e c}$ were used for each functioning mode (with or without circulation) while plotting ratios. It allows demonstrating the nonstationary nature of air temperature reduction in premises of various configurations. Figure 4 shows that maximum values $t_{d e c}$ correspond to premises № 5, while the minimum values - to premises № 3 . It is explained by the sufficiently high specific value of "corner" premises heat loss relatively to "central" premises. 


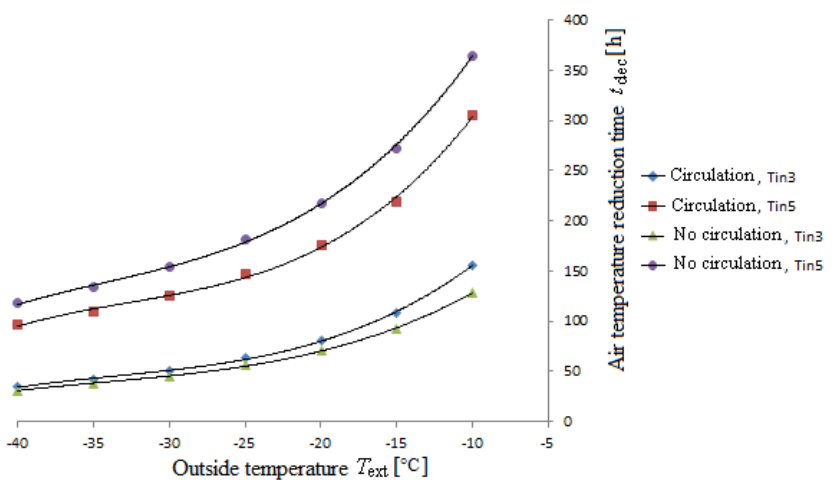

Figure 4. Air temperature reduction times $t_{d e c}$ in premises to "threshold" value $T_{i n}=0{ }^{\circ} \mathrm{C}$.

\section{Summary}

A model of the district heating system of the building, which allows investigating the stability of typical buildings and constructions thermal mode (to analyze cooling processes of the heating system coolant, air temperature reduction in premises of various configurations, as well as exterior envelopments) during heat supply failure, has been developed.

The heating system operation mode influence on the basic characteristics of a building thermal mode has been defined. For example, for the considered object, it have been shown that circulation increases the minimum cooling time of the coolant up to $61.2 \%$, promoting intensive heat and mass transfer in the heating system inner loop. This effect reduces thermal processes stationarity, which is particularly pronounced at the absence of coolant circulation. The influence of circulation on air temperature dynamics in premise is appeared in a lesser degree due to heat exchange processes inertia of the heating system and air in the premise.

Obtained simulation results (a model, dependences, conclusions and ratios) can be used for preventive measures formulation to optimize the basic operations and procedures, aimed at restoring the thermal modes of buildings and constructions in case of heat supply failure.

This work was supported by the Russian Foundation for Basic Research (project 14-08-00057).

\section{References}

1. P. Lauenburg, J. Wollerstrand, Proceedings of the 11th International Building Performance Simulation Association Conference, 150 (Glasgow, Scotland, 2009)

2. M. Wallace, R. McBride, S. Aumi, P. Mhaskar, J. House, T. Salsbury, Chem. Eng. Sci. 69, 45 (2012)

3. S. Privara, Z. Vana, E. Zacekova, Energ. Buildings 55, 341 (2012)

4. M.A. Mishin, Polzunovskii vestnik 1, 146 (2010)

5. V.V. Burstev, A.S. Basi, N.M. Baitinger, Polzunovskii vestnik 1, 147 (2004)

6. A.V. Pugovkin, S.V. Kuprekov, D.V. Abushkin, I.A. Zarechnaya, N.I. Muslimova, Lectures of TUSUR University: Control, computing equipment 22, 293 (2010)

7. A.P. Batista, M.E.A. Freitas, F.G. Jota, Energ. Buildings 75, 368 (2014)

8. M. Zago, A. Casalegno, R. Marchesi, F. Rinaldi, Energies 4, 2115 (2011)

9. O. Ibrahim, F. Fardoun, R. Younes, H. Louahlia-Gualous, Build. Environ. 72, 259 (2014)

10. M. Kiyan, E. Bingöl, M. Melikoglu, A. Albostan, Energy Convers. Manage. 72, 147 (2013)

11. T. Persson, Proceedings of the 45th International Conference of Scandinavian Simulation Society, 199 (Copenhagen, Denmark, 2004) 